\title{
CALIBRATION OF DOSEMETERS USED IN MAMMOGRAPHY WITH DIFFERENT X RAY QUALITIES: EUROMET PROJECT NO. 526
}

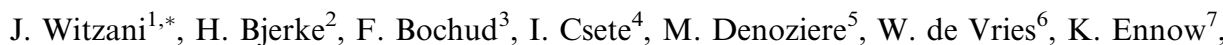
J. E. Grindborg 8 , C. Hourdakis ${ }^{9}$, A. Kosunen ${ }^{10}$, H. M. Kramer ${ }^{11}$, F. Pernicka ${ }^{12}$ and T. Sander ${ }^{13}$

${ }^{1}$ Bundesamt für Eich- und Vermessungswesen (BEV), Arltgasse 35, A-1160 Vienna, Austria

${ }^{2}$ Norwegian Radiation Protection Authority (NRPA), PO Box 55, N-1332 Østerås, Norway

${ }^{3}$ Institut Universitaire de Radiophysique Appliquée (IRA), Grand-Pré 1, CH-1007 Lausanne, Switzerland

${ }^{4}$ Országos Mérésügyi Hivatal (OMH), Németvölgyi út 37-39, H-1124 Budapest, Hungary

${ }^{5}$ Laboratoire Central des Industries Electriques (BNM-LCIE), 33, avenue du Général Leclerc F-92260

Fontenay-aux-Roses, France

${ }^{6} \mathrm{NMi}$ Van Swinden Laboratorium (NMi), Princetonplein 1, NL-3584 CC Utrecht, The Netherlands

${ }^{7}$ National Institute of Radiation Hygiene (SIS), Knapholm 7, DK-2730 Herlev, Denmark

${ }^{8}$ Swedish Radiation Protection Authority (SSI), S-17116 Stockholm, Sweden

${ }^{9}$ Hellenic Ionizing Radiation Calibration Laboratory (HIRCL), Agia Praskevi 15310 Attiki, Greece

${ }^{10}$ Radiation and Nuclear Safety Authority (STUK), PO Box 14, FIN-00881 Helsinki, Finland

${ }^{11}$ Physikalisch-Technische Bundesanstalt (PTB), Bundesallee 100, D-38116 Braunschweig, Germany

${ }^{12}$ International Atomic Energy Agency (IAEA), Wagramer Strasse, A-1020 Vienna, Austria

${ }^{13}$ National Physical Laboratory (NPL), Queens Road, Teddington TW11 0LW, UK

\section{Received June 9 2003, amended September 9 2003, accepted September 192003}

The effect of different $X$ ray radiation qualities on the calibration of mammographic dosemeters was investigated within the framework of a EUROMET (European Collaboration in Measurement Standards) project. The calibration coefficients for two ionization chambers and two semiconductor detectors were established in $\mathbf{1 3}$ dosimetry calibration laboratories for radiation qualities used in mammography. They were compared with coefficients for other radiation qualities, including those defined in ISO 4037-1, with first half value layers in the mammographic range. The results indicate that the choice of the radiation quality is not crucial for instruments with a small energy dependence of the response. However, the radiation quality has to be chosen carefully if instruments with a marked dependence of their response to the radiation energy are calibrated.

\section{INTRODUCTION}

The European Council Directive 97/43/EURATOM ${ }^{(1)}$ on health protection of individuals against the dangers of ionizing radiation in relation to medical exposure provides various measures in order to control patient dose from radiodiagnosis. Mammography is one of the diagnostic techniques which contributes to the patient dose. Dosemeters are important instruments to assess this dose. An adequate calibration of these dosemeters is an essential requirement for correct measurements with these instruments.

A comprehensive comparison of dosemeters used in diagnostic radiology including mammography was conducted in 1990. This exercise was performed in 19 European countries and several publications refer to the findings of the comparison ${ }^{(2)}$. One reference dosemeter for conventional radiology and one for mammography were calibrated at the Physikalisch-Technische Bundesanstalt (PTB) using

*Corresponding author: E1@metrology.at a series of radiation qualities. The reference dosemeters were then sent sequentially to the national metrology centres of the other 18 participating countries. The national centres circulated the dosemeters among the participants, who were asked to calibrate the two reference instruments against their own dosemeter(s) at selected radiation qualities. The calibration factors determined by all participants were sent to the relevant national centres and forwarded to PTB, where all results were analysed. Stability checks of both reference instruments were carried out by PTB several times during the comparison. The differences in the measurements were expressed as the ratio between the calibration factor determined by an individual participant $\left(N_{\text {part }}\right)$ and the mean calibration factor determined by PTB $\left(N_{\text {PTB }}\right)$. Altogether, 162 participants took part in this comparison, with a total of 203 dosemeters.

Considering all dosemeters and radiation qualities, the average of the ratio $N_{\text {part }} / N_{\text {PTB }}$ was close to 1 , indicating that there was no systematic bias in the response of the participants' dosemeters. The 
relative standard deviation of all ratios was only slightly greater than $10 \%$, i.e. in most cases, the error of the measurement was less than $10 \%$. However, it also means that in about one-third of all cases, the error of the measurement was greater than $10 \%$ - a value currently accepted as a reasonable upper limit for clinical measurements in the diagnostic field.

When comparing the results obtained in 1990 with those presented in this report, one should bear in mind that the earlier comparison was carried out by users, whereas this EUROMET project was carried out by national metrology institutes.

In the project EUROMET $364^{(3)}$ a number of European standard laboratories have agreed upon the comparison of their primary air kerma standards for a selected set of $17 \mathrm{X}$ ray qualities used for calibration in the field of diagnostic radiology, including mammography. The results indicated reasonable agreement in the calibration coefficients for the two ionization chambers, which were used as transfer instruments.

The effect of spectra on calibration and measurement with several mammographic ionization chambers was investigated ${ }^{(4)}$. The energy response of 10 commercially available chambers was determined. The chambers showed variation in their air kerma response as a function of beam radiation quality. It was concluded that the combined effect of the chamber's energy dependence of response and its influence on the HVL measurement can result in differences ranging from -1.8 to $+2.5 \%$ in the determination of the mean glandular dose.

A set of $\mathrm{X}$ ray qualities containing different anode (molybdenum, tungsten, rhodium) and filter materials (molybdenum, rhodium, palladium) for mammographic $X$ ray equipment is defined in IEC 1223-3-2:1996 ${ }^{(5)}$. For the calibration of dosemeters used in mammography, for the time being, only qualities produced by a Mo-anode are defined in IEC 1267:1994 ${ }^{(6)}$. Nowadays, only a few standard and calibration laboratories are equipped with $\mathrm{X}$ ray tubes with Mo-anode capable of providing these $\mathrm{X}$ ray qualities for calibration purposes. On the other hand, a number of 'similar' radiation qualities from $\mathrm{X}$ ray tubes with $\mathrm{W}$-anode are available at these laboratories and are worth considering as an alternative to the $\mathrm{X}$ ray qualities defined in IEC 1267. These alternatives include qualities defined by BIPM-CCEMRI [now CCRI (Consultative Committee for Ionising Radiation of the Comité International des Poids et Mesures)]: $1972^{(7)}$ and ISO 4037-1: $1996^{(8)}$ (narrow and high air kerma rate spectra) as well as the $\mathrm{X}$ ray qualities from IEC 1223-3-2, which can be produced by the existing $\mathrm{X}$ ray tubes with $\mathrm{W}$-anode. The availability of all these and other relevant radiation qualities as well as dosemeters/detectors was ascertained by the results of a questionnaire completed by different metrological institutes. Therefore, the EUROMET project no. 526 was initiated in order to validate the different radiation qualities with respect to their suitability for the calibration of dosemeters used in mammography. This EUROMET project was a cooperation in research among various metrological institutes, which were the participants of this project.

\section{INSTRUMENTS AND METHODS}

The participants agreed to circulate four different instruments which are dedicated for measurements in mammography (see Table 1 and Figure 1). They were to be calibrated in the participating laboratories in terms of air kerma. Two of the instruments were ionization chambers which had to be connected to the laboratories' own electrometers. The other two instruments were semiconductor detectors connected to their own electrometers. The owner of the first three instruments is BEV (Bundesamt für Eich- und Vermessungswesen). Unfors Instruments (Sweden) kindly supplied the fourth instrument for this EUROMET project, free of charge by arrangement of SSI, Sweden.

The main task of this EUROMET project was to investigate the suitability of radiation qualities available (at standard laboratories) for the calibration of dosemeters used in mammography, according to the

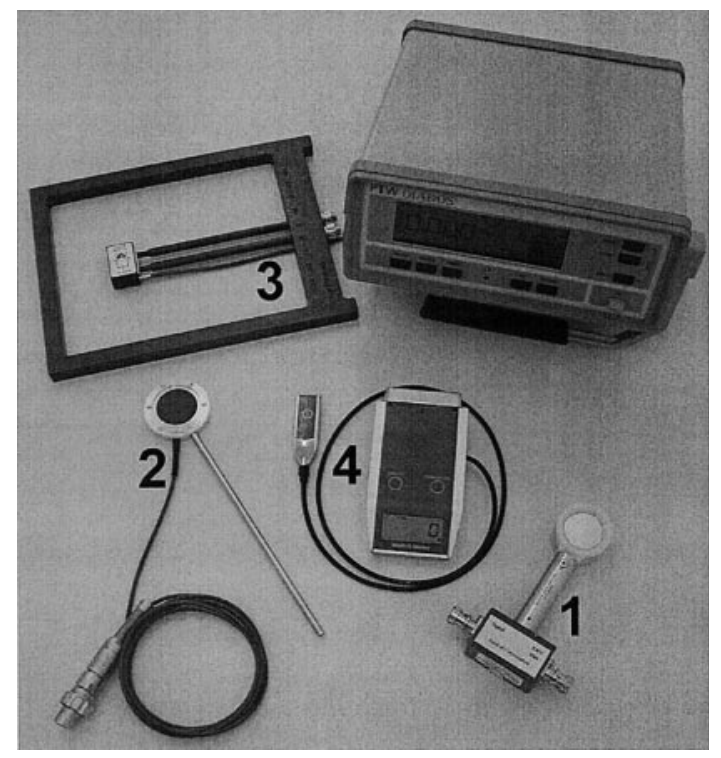

Figure 1. Instruments circulated within the project EUROMET 526: (1) Radcal chamber, (2) PTW chamber, (3) PTW Diados, (4) Unfors 508. 


\section{CALIBRATION OF DOSEMETERS USED IN MAMMOGRAPHY}

requirements of IEC $61674: 1997^{(9)}$. In this standard, the reference parameters for the radiation quality in mammography are: $28 \mathrm{kV}$, Mo-anode, total filtration: $30 \mu \mathrm{m}$ Mo as defined by IEC 1267:1994, but without the use of a phantom. According to IEC 61674:1997, the minimum rated range of dosemeters used in mammography must comply with the requirements given in Table 2.

The second purpose of this EUROMET project was to compare the calibration results among the laboratories.

For the calibration of dosemeters, the radiation qualities given in Table 3 were used as far as they were available at the different laboratories. Some photon fluence spectra of these radiation qualities measured at BEV, NPL and PTB are given in Figures 2-4. Spectra for radiation qualities defined in ISO 4037 are given in Reference 8.

The calibration of the dosemeter(s)/detector(s) was carried out in the laboratories of the participants in the period from December 2000 to May 2002. During this period, the stability of each instrument was checked several times in the dosimetry laboratory of the BEV, while the stability checks of the comparison, which was conducted in 1990 and which was mentioned in the Introduction, were carried out by PTB. The uncertainty $U_{\text {stab }}$ for the stability of each instrument was derived from these data using Equation 1:

$$
U_{\text {stab }}=2^{*} \sqrt{\frac{\sum_{i=1}^{m} s_{i}^{2}}{m}}(k=2),
$$

with $s_{\mathrm{i}}$ being the standard deviation of the calibration coefficients for the radiation quality $i$ and $m$ being the total number of radiation qualities used for the stability check. The results are given in the last column of Table 1 . The uncertainty $U_{\text {stab }}$ for the instrument Unfors 508 appeared to be much larger for attenuated than for unattenuated beam qualities. This can probably be attributed to the fact that the air kerma rate of the attenuated beam qualities available at the BEV was at the lower end of the measurement range of the instrument. Nevertheless, Equation 1 was also applied in this case.

\section{RESULTS}

\section{General}

In Figures 5-8, all calibration coefficients $N_{\mathrm{k}}$ in terms of air kerma are plotted against the first half value layer (1st HVL) $x$ of the corresponding radiation quality. All uncertainty bars are related to the expanded uncertainty $U_{\mathrm{k}}$ (coverage factor $k=2$ ) of the calibration coefficients. The polynomial regression $N_{\mathrm{p}, \mathrm{a}}(x)$ (maximum 4 th order), shown in each of these diagrams, was calculated using all calibration coefficients. The dotted lines in these diagrams indicate the expanded uncertainty $U_{\mathrm{p}, \mathrm{a}}(x)(k=2)$ of the polynomial regression.

In the next step, the calibration coefficients were sorted into seven groups of radiation qualities, shown in Table 3. The ratio of each calibration coefficient $N_{\mathrm{k}}$ and the polynomial regression $N_{\mathrm{p}, \mathrm{a}}(x)$ at the 1 st $\mathrm{HVL}$ of the corresponding

Table 1. Instruments calibration in EUROMET 526.

\begin{tabular}{|c|c|c|c|c|c|}
\hline Instrument & Model/type & Manufacturer & $\begin{array}{l}\text { Nominal } \\
\text { response }\end{array}$ & $\begin{array}{l}\text { Reference in } \\
\text { this work }\end{array}$ & $\begin{array}{c}\text { Stability } \\
U_{\text {stab }}(k=2)\end{array}$ \\
\hline 1 ion. chamber ${ }^{*}$ & Model $10 \times 5-6 \mathrm{M} 6 \mathrm{~cm}^{3}$ & Radcal & $0.2 \mathrm{nC} \mathrm{mGy}^{-1}$ & Radcal chamber & $0.29 \%$ \\
\hline 1 ion. chamber ${ }^{*}$ & Type $773341 \mathrm{~cm}^{3}$ & PTW & $0.05 \mathrm{nC} \mathrm{mGy}^{-1}$ & PTW chamber & $0.34 \%$ \\
\hline 1 dosemeter & Diados type $11003-$ & PTW & $20 \mathrm{nC} \mathrm{mGy}^{-1}$ & PTW Diados & $0.45 \%$ \\
\hline (semicond. type) & Detector type 60005 & & & & \\
\hline $\begin{array}{l}1 \text { dosemeter } \\
\text { (semicond. type) }\end{array}$ & Mult-O-Meter model 508 & Unfors & - & Unfors 508 & $1.8 \%$ \\
\hline
\end{tabular}

* A high voltage supply and an electrometer provided by each participating laboratory were necessary to calibrate the ionization chamber

Table 2. Requirements of IEC 61674:1997 for dosemeters used in mammography.

\begin{tabular}{lcccc}
\hline Radiation quality & Anode material & Tube voltage & Added filtration & $\begin{array}{c}\text { Limits of variation } \\
\text { of response }\end{array}$ \\
\hline Unattenuated beam & Mo & $25-35 \mathrm{kV}$ & $30 \mu \mathrm{m} \mathrm{Mo}$ & $\pm 5 \%$ \\
Attenuated beam & Mo & $25-35 \mathrm{kV}$ & $30 \mu \mathrm{m} \mathrm{Mo}+2 \mathrm{mmAl}$ & $\pm 5 \%$ \\
\hline
\end{tabular}


J. WITZANI ET AL.

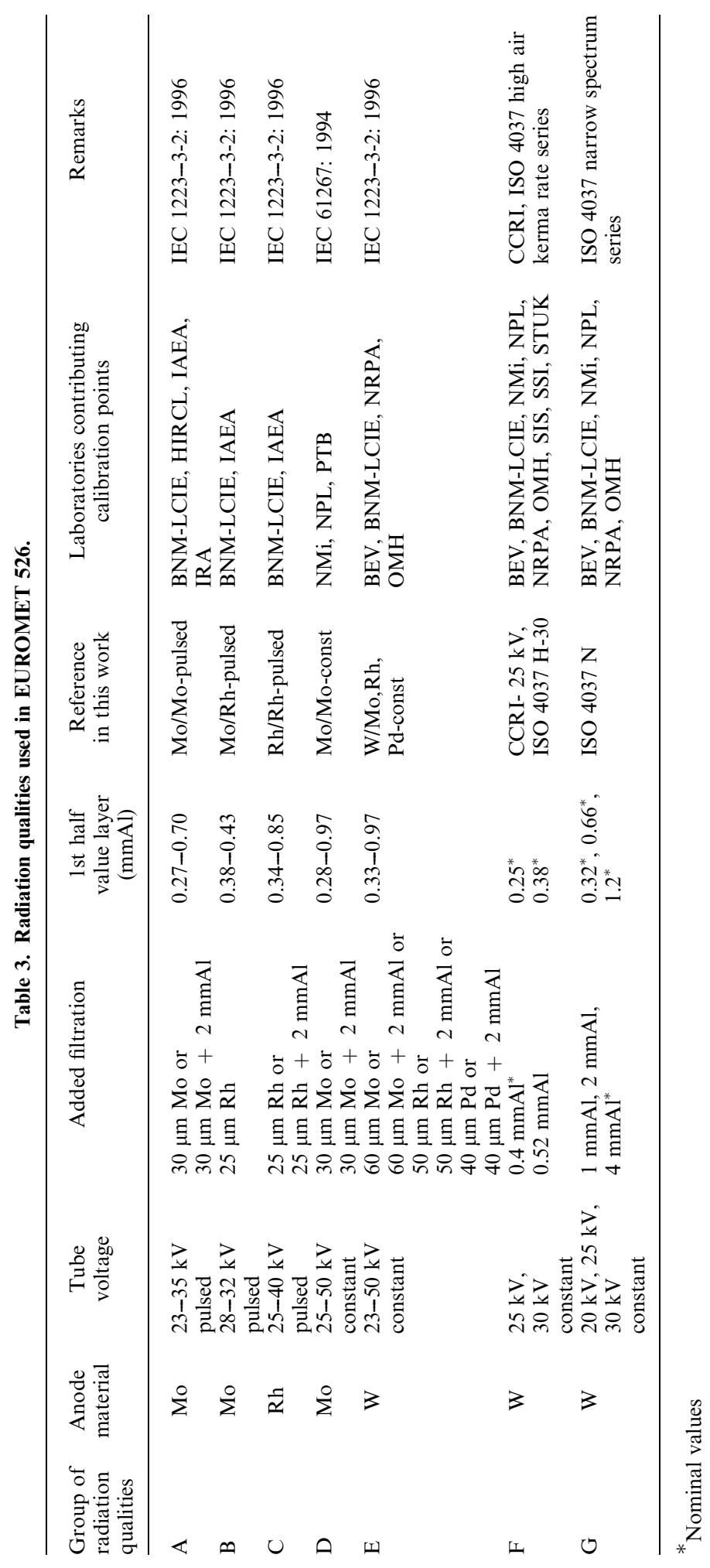


CALIBRATION OF DOSEMETERS USED IN MAMMOGRAPHY
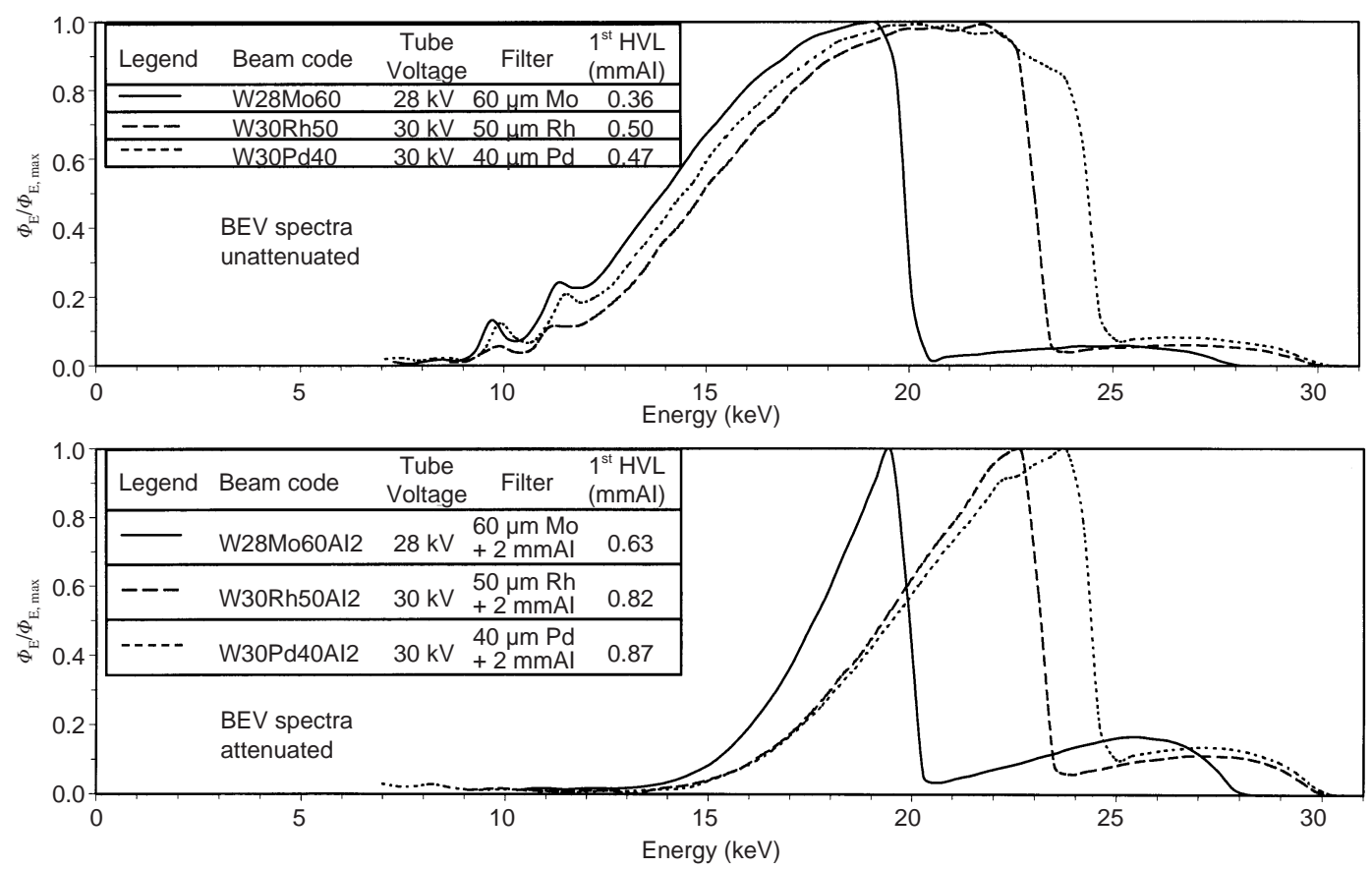

Figure 2. Photon fluence spectra of X rays emitted by a tungsten target and filtered by different material, measured at BEV.
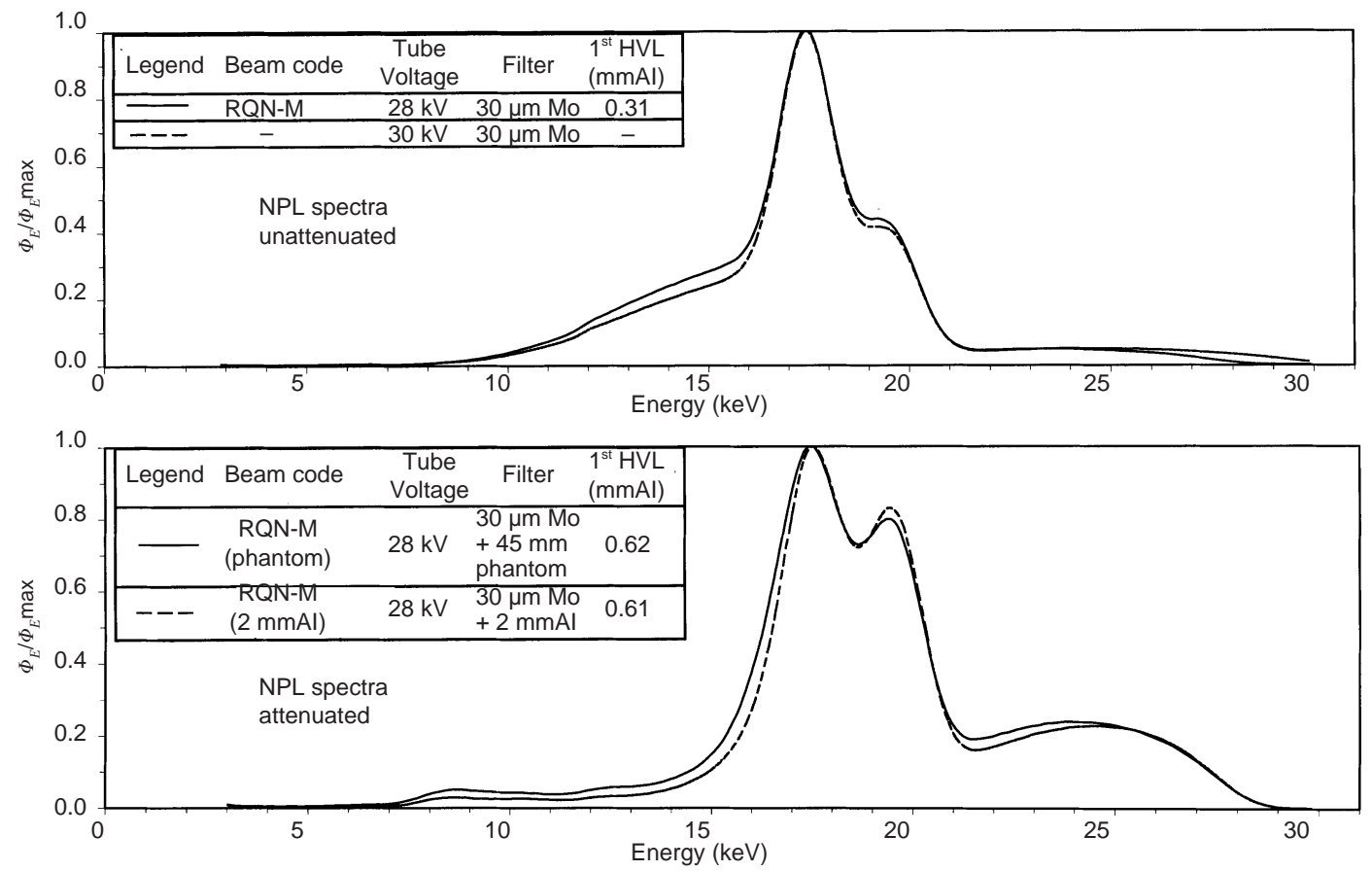

Figure 3. Photon fluence spectra of $\mathrm{X}$ rays emitted by a molybdenum target and filtered by different material, measured at NPL. Note the similarity between the attenuated spectra obtained by an additional filter of a $45 \mathrm{~mm}$ thick breast equivalent phantom and of $2 \mathrm{~mm}$ aluminium. 


\section{J. WITZANI ET AL.}

radiation quality was calculated. Furthermore, the ratio of each calibration coefficient $N_{\mathrm{k}}$ and the mean $N_{\text {mean }}$ of all calibration coefficients was calculated for each instrument. The ratios $N_{\mathrm{k}} / N_{\text {mean }}$ indicate the total spread of the calibration coefficients normalised to $N_{\text {mean }}$, whereas the ratios $N_{\mathrm{k}} / N_{\mathrm{p}, \mathrm{a}}(x)$ show their spread relative to the polynomial regression. Therefore, the calibration results from the different groups of radiation qualities with different 1st HVLs can be compared more easily, in particular for instruments with a marked energy dependence of their response. The frequency distribution of all ratios was plotted for each group of radiation qualities and each instrument (see Figures 9-12). These figures show that the experiments did not reveal any significant difference in the values of the calibration coefficients obtained in pulsed or constant potential beams.

In the following paragraphs, the results for the four instruments involved in this investigation are discussed.

\section{Radcal chamber}

Despite the large variety of radiation qualities used in this exercise, most of the calibration coefficients are within $\pm 2 \%$ (see Figure 5). This means that this chamber can be calibrated within this limit at any HVL irrespective of the type of $\mathrm{X}$ ray tube and/or filter chosen.

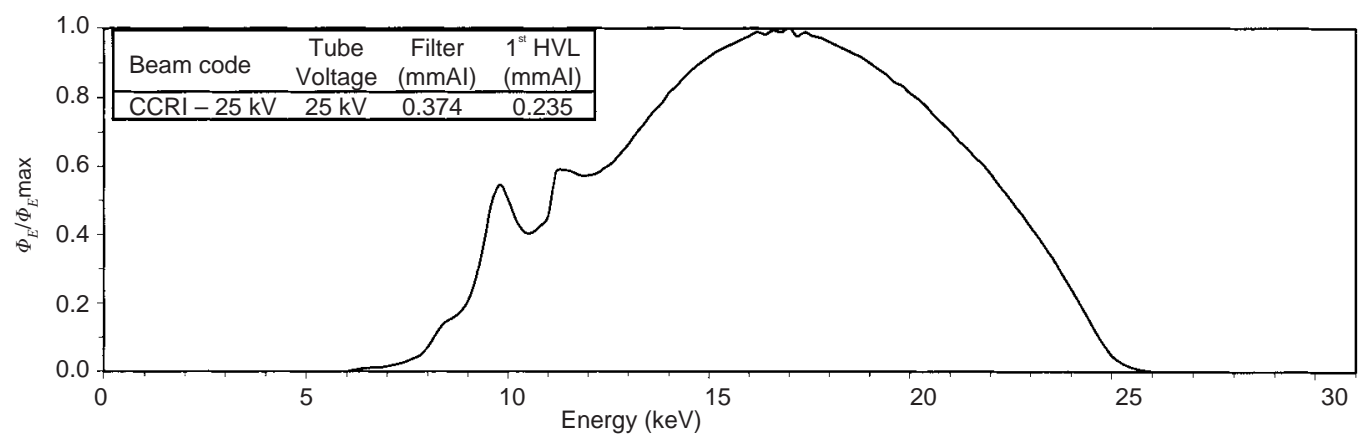

Figure 4. Photon fluence spectrum of the radiation quality CCRI $25 \mathrm{kV}$, measured at PTB.

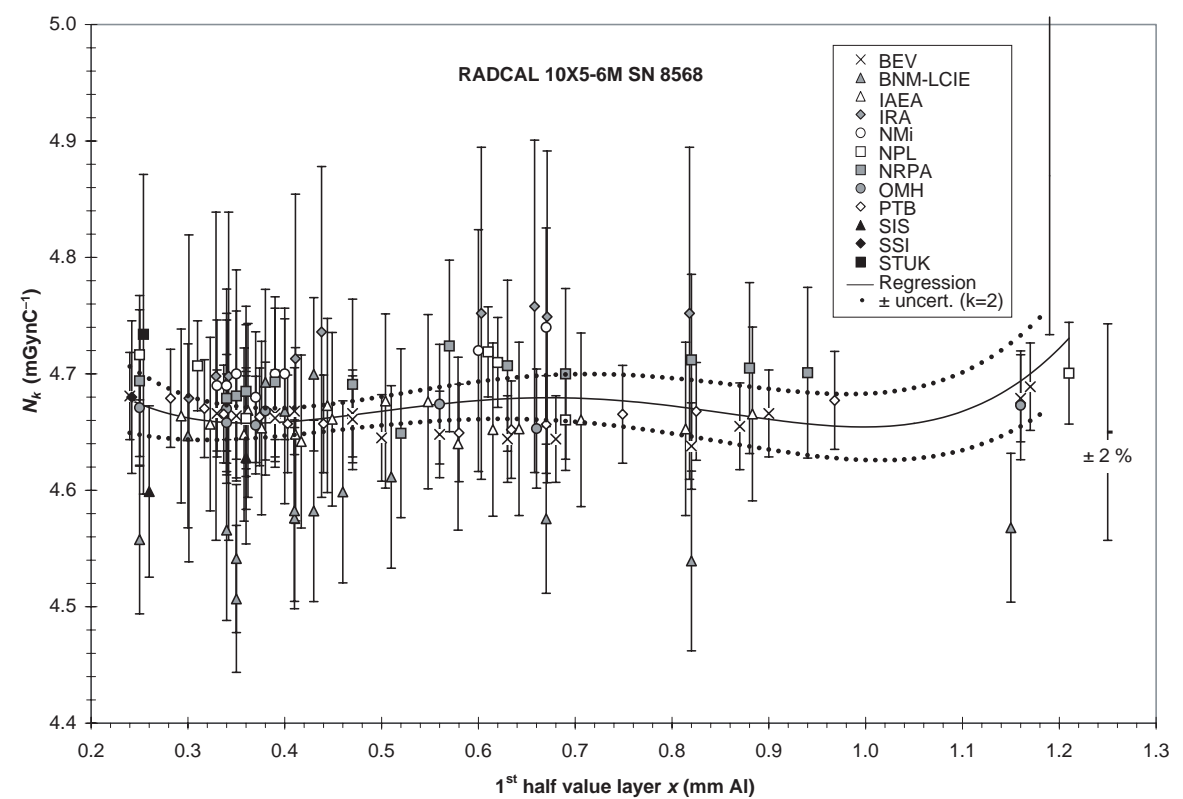

Figure 5. All air kerma calibration coefficients $N_{\mathrm{k}}$ against first half value layer $x$ of the radiation qualities for Radcal chamber. The polynomial regression $N_{\mathrm{p}, \mathrm{a}}(x)$ was calculated from all calibration coefficients. 


\section{CALIBRATION OF DOSEMETERS USED IN MAMMOGRAPHY}

Because of the flat energy dependence of the response, the calibration accuracy between the laboratories can be judged in the best way using this instrument. The ratio of each calibration coefficient $N_{\mathrm{k}}$ and the value of the polynomial regression $N_{\mathrm{p}, \mathrm{a}}(x)$ at the mean 1st HVL, $x_{\mathrm{o}}$, of the corresponding radiation quality from primary standard laboratories was plotted in the Figures 13-16.

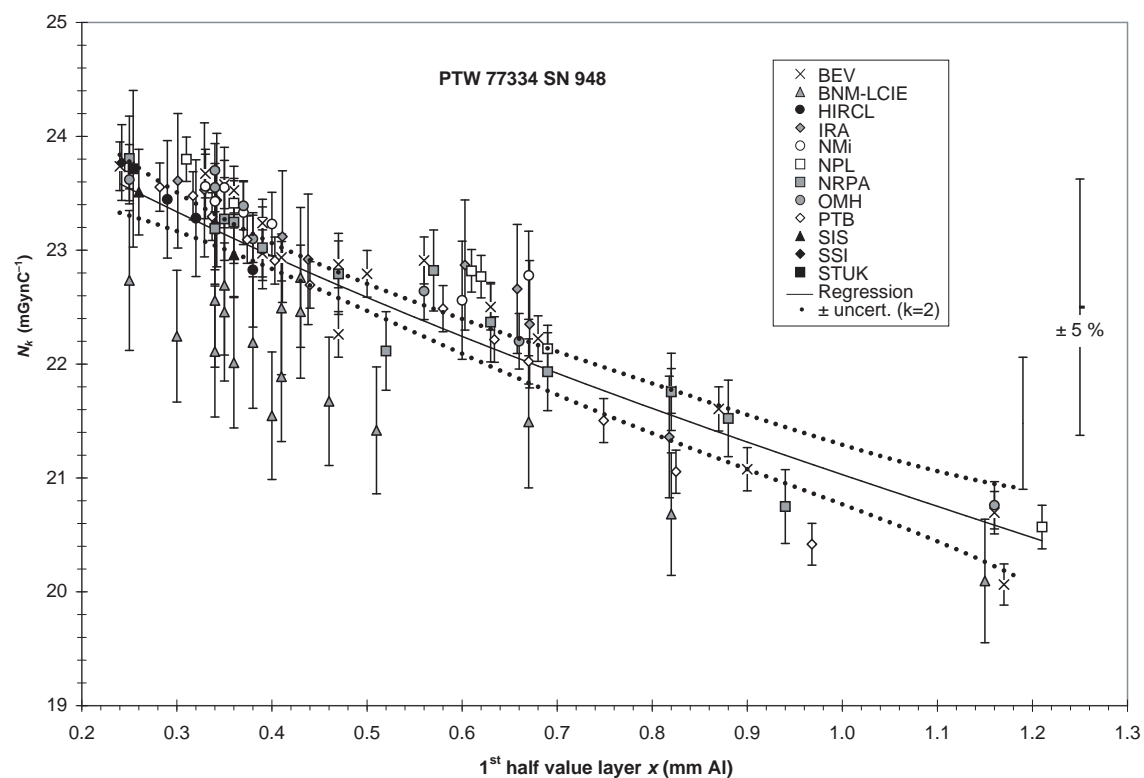

Figure 6. All air kerma calibration coefficients $N_{\mathrm{k}}$ against first half value layer $x$ of the radiation qualities for PTW chamber. The polynomial regression $N_{\mathrm{p}, \mathrm{a}}(x)$ was calculated from all calibration coefficients.

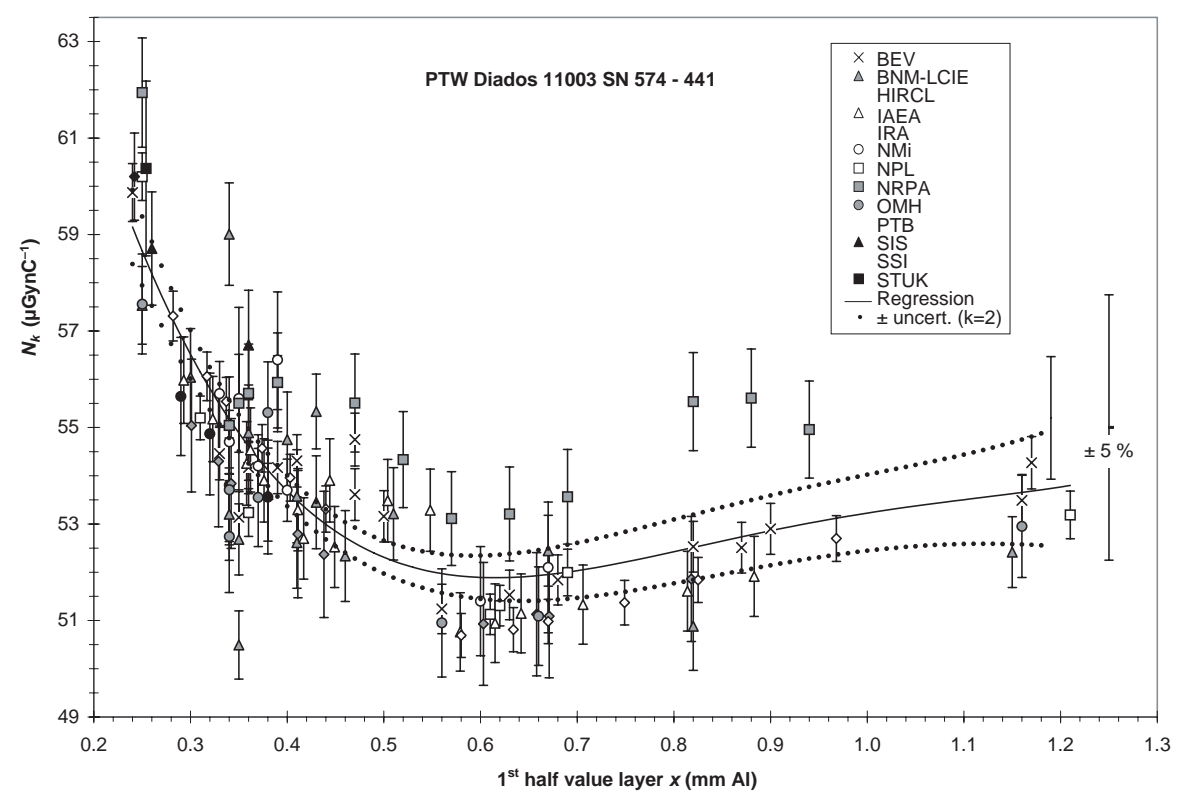

Figure 7. All air kerma calibration coefficients $N_{\mathrm{k}}$ against first half value layer $x$ of the radiation qualities for PTW Diados. The polynomial regression $N_{\mathrm{p}, \mathrm{a}}(x)$ was calculated from all calibration coefficients. 
Furthermore, a reference value $N_{\text {ref }}$ was determined for each radiation quality as the mean of the calibration coefficients, given by those laboratories that used a primary standard for the calibration. The expanded uncertainty $U_{\text {ref }}(k=2)$ of the reference value $N_{\text {ref }}$ was calculated from the following Equation 2:

$$
U_{\text {ref }}=2^{*} \sqrt{\frac{\sum_{i=1}^{p}\left(N_{k, i}-N_{r e f}\right)^{2}}{p^{*}(p-1)}}
$$

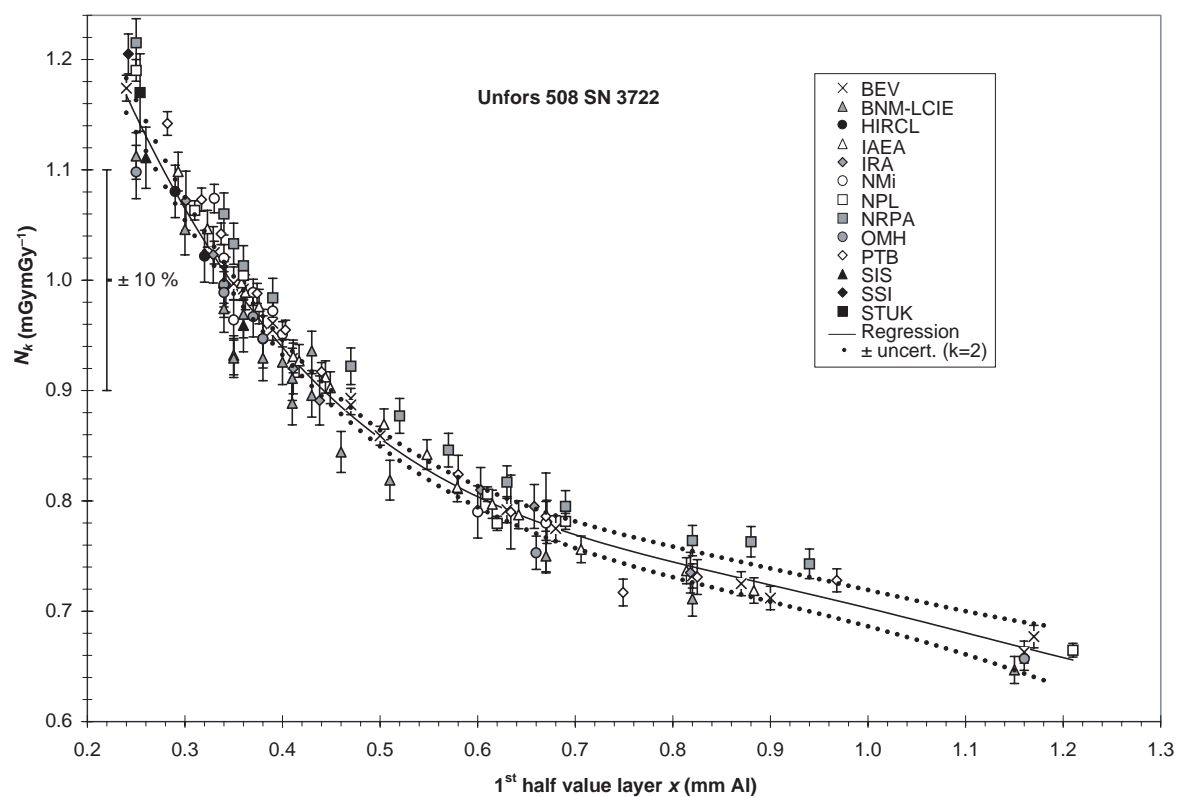

Figure 8. All air kerma calibration coefficients $N_{\mathrm{k}}$ against first half value layer $x$ of the radiation qualities for Unfors 508 . The polynomial regression $N_{\mathrm{p}, \mathrm{a}}(x)$ was calculated from all calibration coefficients.

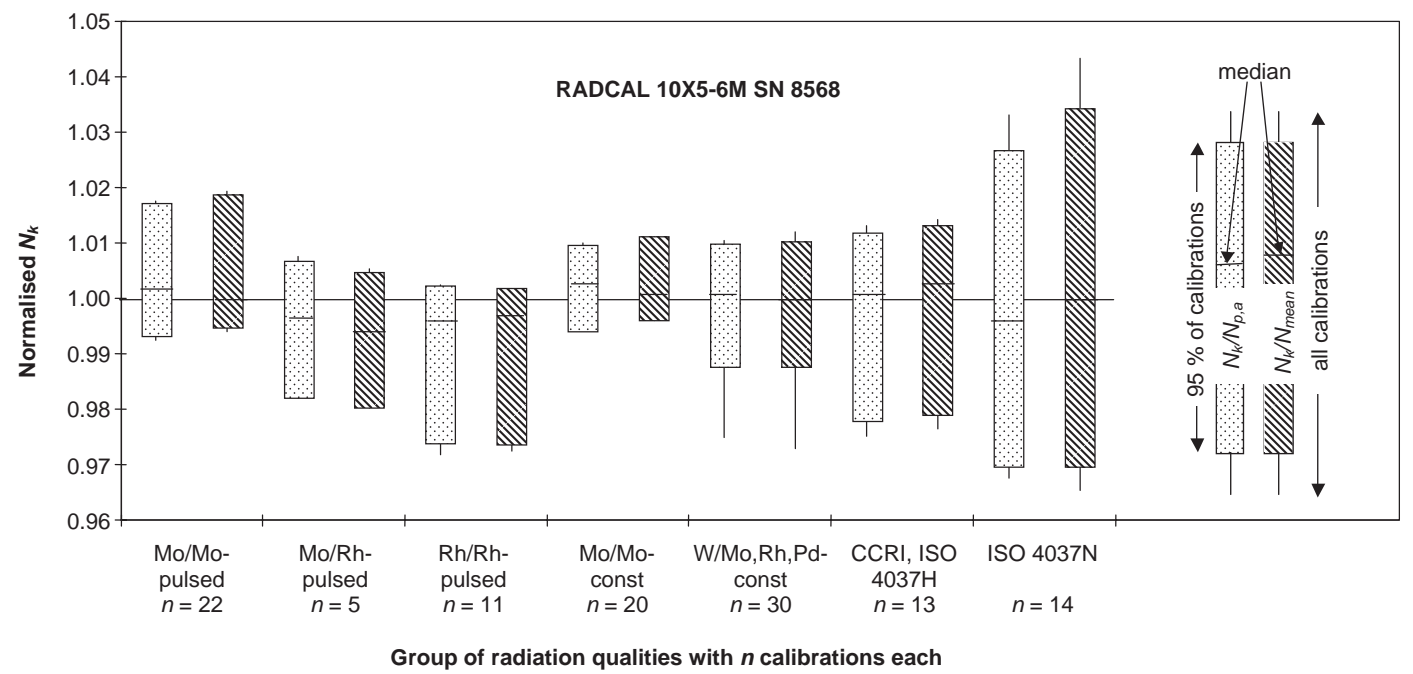

Figure 9. Frequency distribution of the ratios of the air kerma calibration coefficients $N_{\mathrm{k}}$ and the value of the polynomial regression $N_{\mathrm{p}, \mathrm{a}}(x)$ and the mean $N_{\text {mean }}$ of all calibration coefficients, respectively, for Radcal chamber. See Table 3 for legend of groups of radiation qualities. 


\section{CALIBRATION OF DOSEMETERS USED IN MAMMOGRAPHY}

with $N_{\mathrm{k}, \mathrm{i}}$ being the air kerma calibration coefficient of the $i$-th laboratory and $p$ being the number of primary laboratories contributing to the value of $N_{\text {ref. }}$. The ratios of $N_{\mathrm{k}}$ and $N_{\text {ref }}$ are given in the Figures 13-16. Their expanded uncertainty $U_{\mathrm{k}, \mathrm{ref}}$ $(k=2)$ was calculated using Equation 3:

$$
U_{k, r e f}=\frac{N_{k}}{N_{r e f}} * \sqrt{\left(\frac{U_{k}}{N_{k}}\right)^{2}+\left(\frac{U_{r e f}}{N_{r e f}}\right)^{2}}
$$

For most of the results, the deviation of the ratios from unity is less than the expanded uncertainty $U_{\mathrm{k}, \mathrm{ref}}$, which indicates a good agreement among the laboratories.

\section{PTW chamber}

This chamber shows an energy dependence of the calibration coefficients of more than $\pm 5 \%$

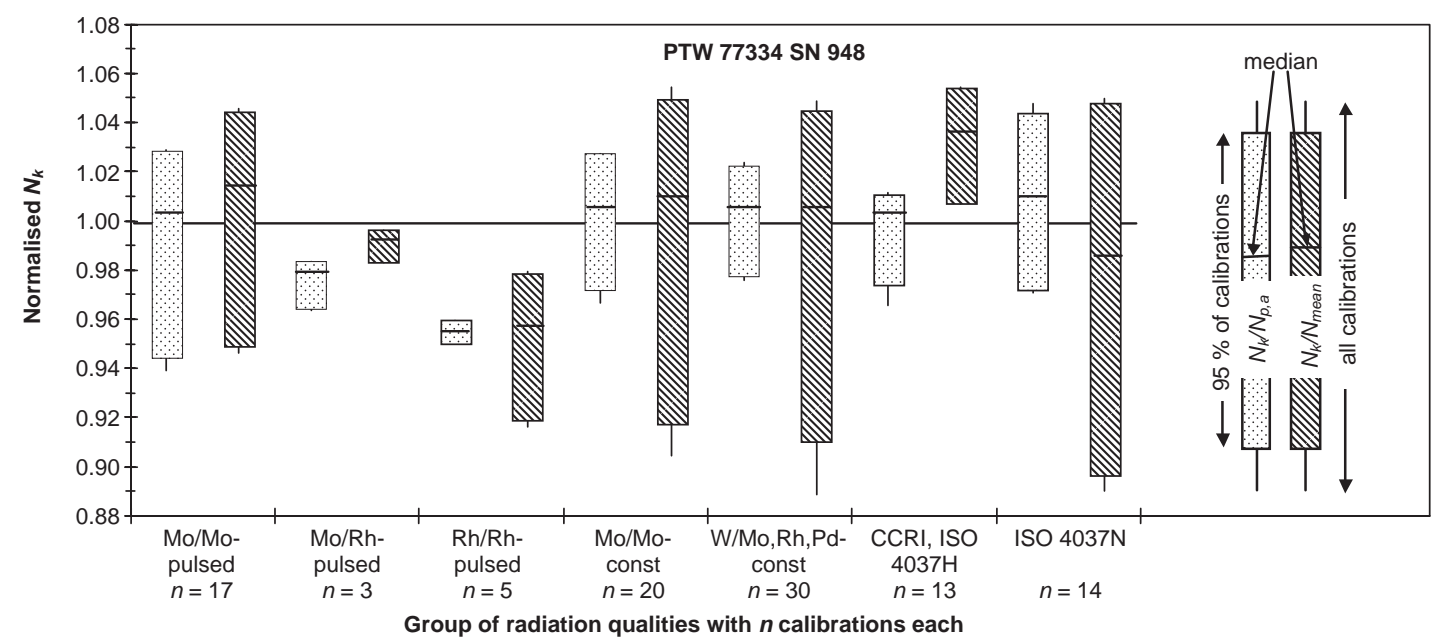

Figure 10. Frequency distribution of the ratios of the air kerma calibration coefficients $N_{\mathrm{k}}$ and the value of the polynomial regression $N_{\mathrm{p}, \mathrm{a}}(x)$ and the mean $N_{\text {mean }}$ of all calibration coefficients, respectively, for PTW chamber. See Table 3 for legend of groups of radiation qualities.

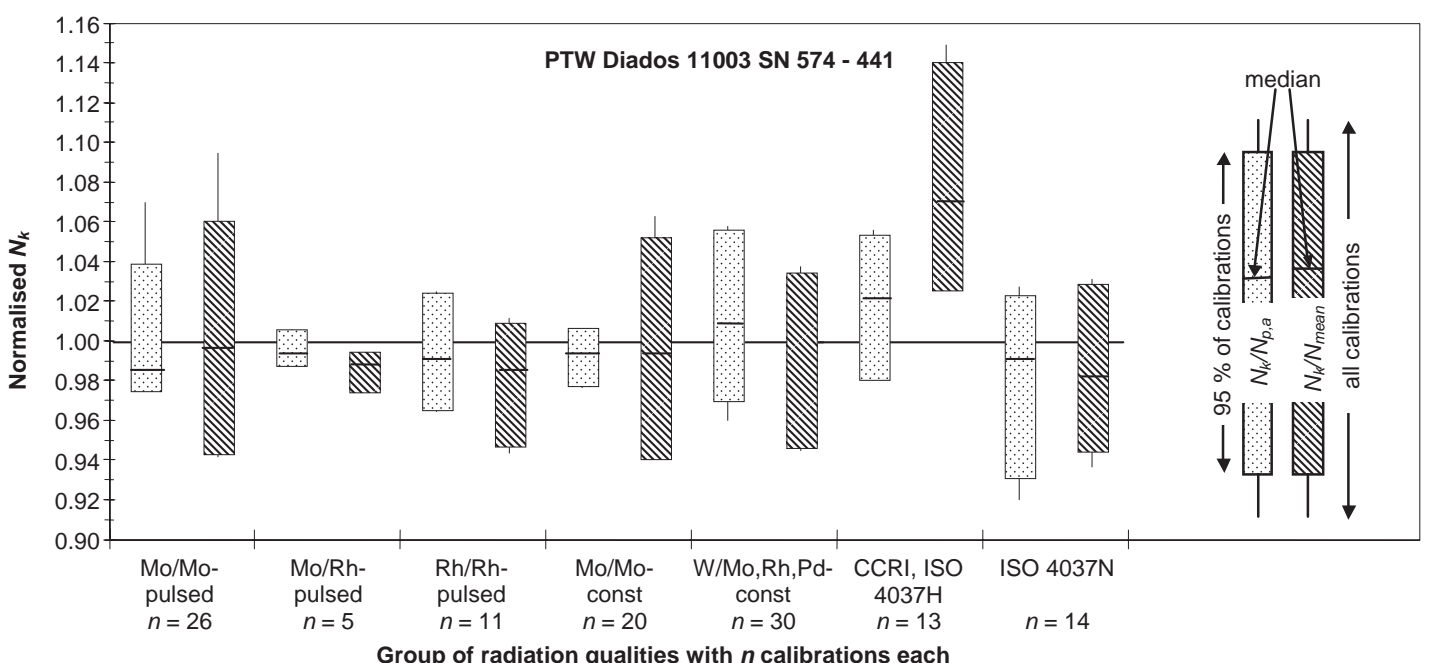

Figure 11. Frequency distribution of the ratios of the air kerma calibration coefficients $N_{\mathrm{k}}$ and the value of the polynomial regression $N_{\mathrm{p}, \mathrm{a}}(x)$ and the mean $N_{\text {mean }}$ of all calibration coefficients, respectively, for PTW Diados. See Table 3 for legend of groups of radiation qualities. 
over the whole range of HVLs investigated (see Figure 6). However, at any given HVL, the difference in the calibration coefficients for different radiation qualities is smaller and not significant in most cases.

\section{PTW Diados}

The energy dependence of the calibration coefficients is pronounced over the whole range of HVLs with a minimum in the range of HVLs of

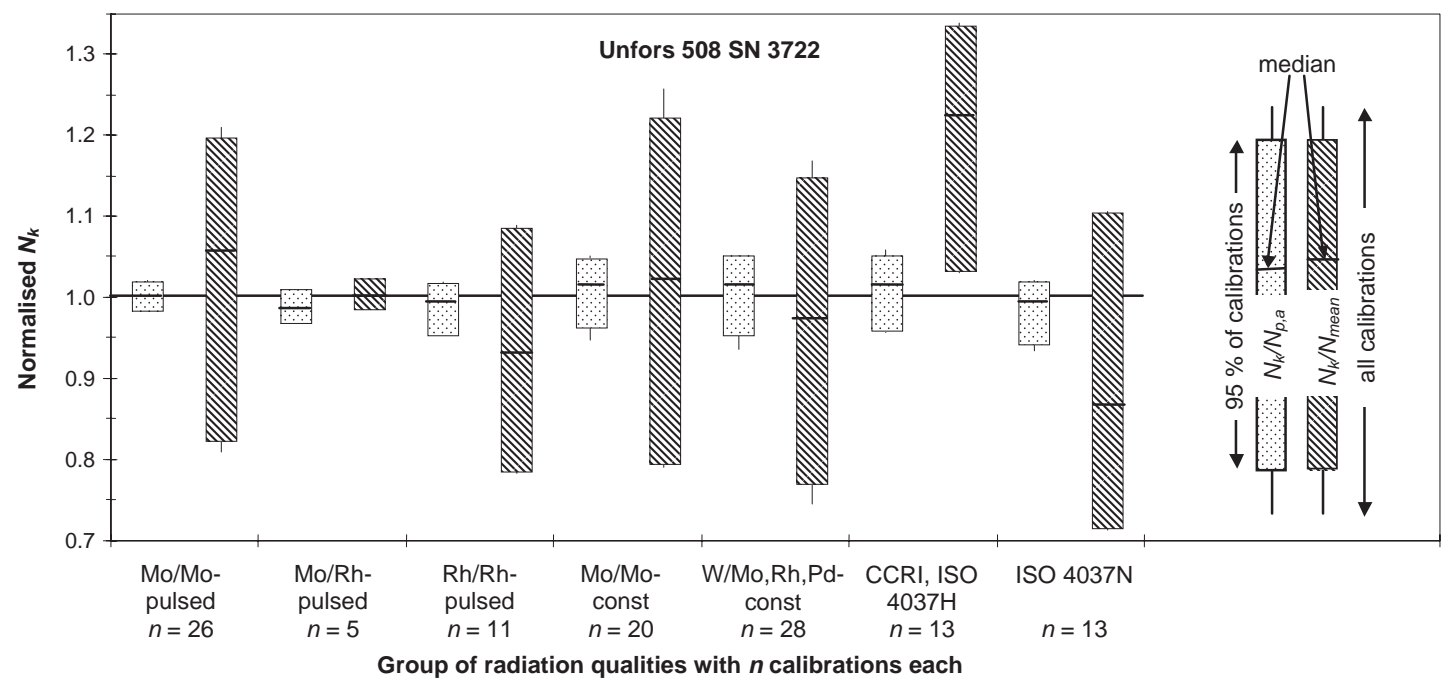

Figure 12. Frequency distribution of the ratios of the air kerma calibration coefficients $N_{\mathrm{k}}$ and the value of the polynomial regression $N_{\mathrm{p}, \mathrm{a}}(x)$ and the mean $N_{\text {mean }}$ of all calibration coefficients, respectively, for Unfors 508 . See Table 3 for legend of groups of radiation qualities.

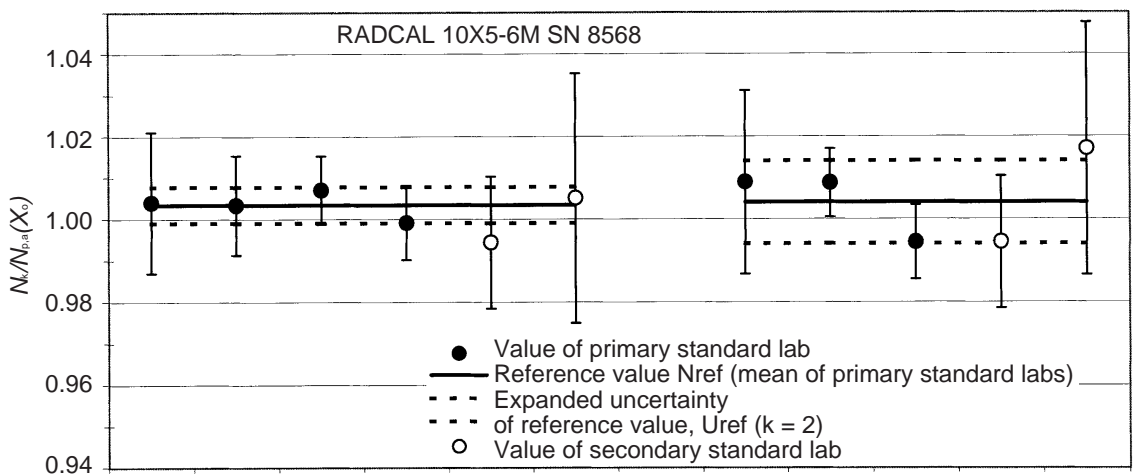

\begin{tabular}{|c|c|c|c|c|c|c|c|c|c|c|}
\hline $\begin{array}{c}\text { Radiation } \\
\text { quality }\end{array}$ & \multicolumn{5}{|c|}{$\begin{array}{c}\text { Mo/Mo, unattenuated } \\
\text { mean } 1^{\text {st }} \mathrm{HVL}: X_{0}=0.327 \mathrm{mmAl}\end{array}$} & \multicolumn{5}{|c|}{$\begin{array}{c}\text { Mo/Mo, attenuated } \\
\text { mean } 1^{\text {st }} \mathrm{HVL}: X_{0}=0.615 \mathrm{mmAl}\end{array}$} \\
\hline Laboratory & $\begin{array}{ll}\text { BNM- } & \mathrm{NMi} \\
\text { LCIE }\end{array}$ & NPL & PTB & IAEA & IRA & $\mathrm{NMi}$ & NPL & PTB & IAEA & IRA \\
\hline Tube voltage & pulsed const. & const. & const. & pulsed & pulsed & const. & const. & const. & pulsed & pulșed \\
\hline $1^{\text {st }} \mathrm{HVL}(\mathrm{mmAl})$ & $0.34 \quad 0.34$ & 0.31 & 0.317 & 0.358 & 0.329 & 0.60 & 0.61 & 0.634 & 0.615 & 0.658 \\
\hline $\begin{array}{c}N_{k} / N_{\text {ret }} \\
\pm \text { expanded } \\
\text { uncertainty } \\
(\mathrm{k}=2)\end{array}$ & $\begin{array}{cc}1.001 & 1.000 \\
\pm 0.018 & \pm 0.013\end{array}$ & $\begin{array}{r}1.004 \\
\pm 0.009\end{array}$ & $\begin{array}{c}0.996 \\
\pm 0.010\end{array}$ & $\begin{array}{c}0.991 \\
\pm 0.016\end{array}$ & $\begin{array}{r}1.002 \\
\pm 0.030\end{array}$ & $\begin{array}{l}1.005 \\
+0.024\end{array}$ & $\begin{array}{r}1.005 \\
\pm 0.013\end{array}$ & $\begin{array}{r}0.990 \\
\pm 0.013\end{array}$ & $\begin{array}{c}0.990 \\
\pm 0.019\end{array}$ & $\begin{array}{r}1.013 \\
\pm 0.032\end{array}$ \\
\hline
\end{tabular}

Figure 13. Ratio of air kerma calibration coefficients $N_{\mathrm{k}}$ and the value of the polynomial regression $N_{\mathrm{p}, \mathrm{a}}\left(x_{\mathrm{o}}\right)$ of all air kerma calibration coefficients at the mean 1st HVL $x_{\mathrm{o}}$ of unattenuated and attenuated radiation qualities emitted from a Mo-target and $30 \mu \mathrm{m}$ Mo-filter at a tube voltage of $28 \mathrm{kV}$ for Radcal chamber. Note: The mean 1st HVL was calculated from the 1st HVL of radiation qualities from primary standard laboratories. 


\section{CALIBRATION OF DOSEMETERS USED IN MAMMOGRAPHY}

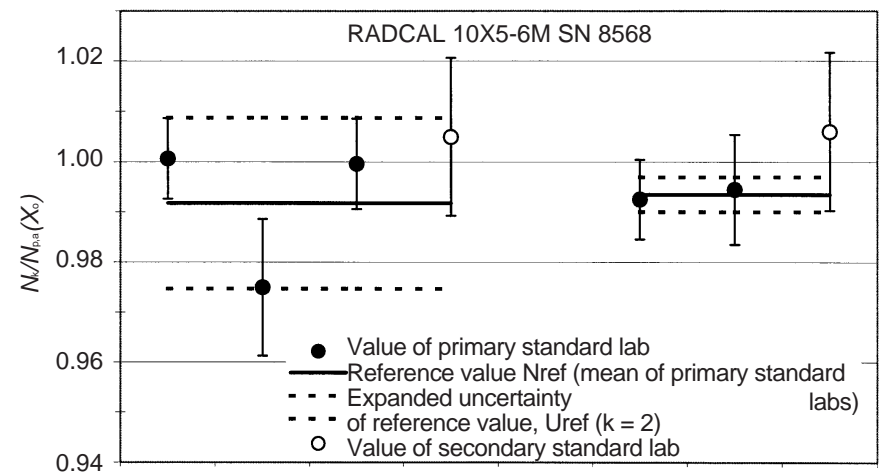

\begin{tabular}{|c|cccc|ccc|}
\hline $\begin{array}{c}\text { Radiation } \\
\text { quality }\end{array}$ & \multicolumn{3}{|c|}{ W/Mo, unattenuated } & \multicolumn{3}{c|}{ W/Mo, attenuated } \\
mean $1^{\text {st }} \mathrm{HVL}: X_{\circ}=0.360$ & $\mathrm{mmAl}$ & mean $1^{\text {st }} \mathrm{HVL}: X_{0}=0.645 \mathrm{mmAl}$ \\
\hline Laboratory & BEV & $\begin{array}{c}\text { BNM- } \\
\text { LCIE }\end{array}$ & OMH & NRPA & BEV & OMH & NPRA \\
\hline Tube voltage & 28 & 30 & 30 & 28 & 28 & 30 & 28 \\
\hline $1^{\text {st }} \mathrm{HVL}(\mathrm{mmAl})$ & 0.36 & 0.35 & 0.37 & 0.35 & 0.63 & 0.66 & 0.63 \\
\hline $\begin{array}{c}N_{k} / N_{\text {ref }} \\
\pm \text { expanded } \\
\begin{array}{c}\text { uncertainty } \\
(\mathrm{k}=2)\end{array}\end{array}$ & $\begin{array}{c}1.009 \\
\pm 0.019\end{array}$ & $\begin{array}{c}0.983 \\
\pm 0.022\end{array}$ & $\begin{array}{c}1.008 \\
\pm 0.019\end{array}$ & $\begin{array}{c}1.013 \\
\pm 0.023\end{array}$ & $\begin{array}{c}0.999 \\
\pm 0.019\end{array}$ & $\begin{array}{c}1.001 \\
\pm 0.020\end{array}$ & $\begin{array}{c}1.013 \\
\pm 0.023\end{array}$ \\
\hline
\end{tabular}

Figure 14. Ratio of air kerma calibration coefficients $N_{\mathrm{k}}$ and the value of the polynomial regression $N_{\mathrm{p}, \mathrm{a}}\left(x_{\mathrm{o}}\right)$ of all air kerma calibration coefficients at the mean 1st HVL $x_{\mathrm{o}}$ of unattenuated and attenuated radiation qualities emitted from a W-target and $60 \mu \mathrm{m}$ Mo-filter at a constant tube voltage for Radcal chamber. Note: The mean 1st HVL was calculated from the 1st HVL of radiation qualities from primary standard laboratories.

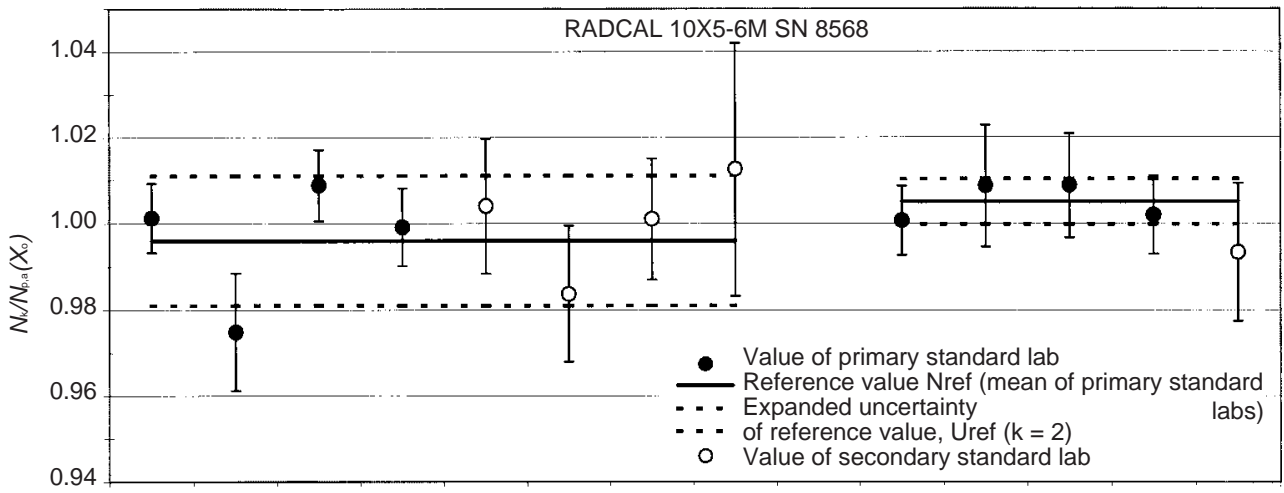

\begin{tabular}{|c|c|c|c|c|c|c|c|c|c|c|c|c|}
\hline $\begin{array}{l}\text { Radiation } \\
\text { quality }\end{array}$ & \multicolumn{7}{|c|}{$\begin{array}{c}\text { CCRI-25 kV } \\
\text { mean } 1^{\text {st }} \mathrm{HVL}: X_{0}=0.248 \mathrm{mmAl}\end{array}$} & \multicolumn{5}{|c|}{$\begin{array}{c}\text { ISO } 4037 \mathrm{H}-30) \\
\text { mean } 1^{\text {st }} \mathrm{HVL}: X_{\circ}=0.398 \mathrm{mmAl}\end{array}$} \\
\hline Laboratory & $\begin{array}{l}\text { BNM- } \\
\text { LCIE }\end{array}$ & NPL & $\mathrm{OMH}$ & NPRA & SIS & SSI & STUK & BEV & $\begin{array}{l}\text { BNM- } \\
\text { LCIE }\end{array}$ & $\mathrm{NMi}$ & $\mathrm{OMH}$ & SIS \\
\hline $1^{1^{s t}} \mathrm{HVL}(\mathrm{mmAl})$ & 0.25 & 0.25 & 0.25 & 0.25 & 0.25 & 0.242 & 0.254 & 0.39 & 0.43 & 0.39 & 0.38 & 0.36 \\
\hline $\begin{array}{c}N_{\mathrm{k}} / N_{\text {ret }} \\
\pm \text { expanded } \\
\text { uncertainty } \\
(\mathrm{k}=2)\end{array}$ & $\begin{array}{c}1.0050 .979 \\
\pm 0.017 \pm 0.020\end{array}$ & $\begin{array}{c}1.013 \\
\pm 0.017\end{array}$ & $\begin{array}{r}1.003 \\
\pm 0.018\end{array}$ & $\begin{array}{c}1.008 \\
\pm 0.022\end{array}$ & $\begin{array}{r}0.988 \\
\pm 0.022\end{array}$ & $\begin{array}{r}1.005 \\
\pm 0.021\end{array}$ & $\begin{array}{c}1.017 \\
\pm 0.033\end{array}$ & $\begin{array}{c}0.996 \\
\pm 0.010\end{array}$ & $\begin{array}{c}1.004 \\
\pm 0.015\end{array}$ & $\begin{array}{c}1.004 \\
\pm 0.013\end{array}$ & $\begin{array}{c}0.997 \\
\pm 0.010\end{array}$ & $\begin{array}{r}0.988 \\
\pm 0.017\end{array}$ \\
\hline
\end{tabular}

Figure 15. Ratio of air kerma calibration coefficients $N_{\mathrm{k}}$ and the value of the polynomial regression $N_{\mathrm{p}, \mathrm{a}}\left(x_{\mathrm{o}}\right)$ of all air kerma calibration coefficients at the mean 1st HVL $x_{\mathrm{o}}$ of radiation qualities defined by the CCRI and the international standard ISO 4037-1:1996 (high air kerma rate series) at a constant tube voltage for Radcal chamber. Note: The mean 1st HVL was calculated from the 1st HVL of radiation qualities from primary standard laboratories. 


\section{J. WITZANI ET AL.}

about 0.6 to $0.7 \mathrm{mmAl}$ (see Figure 7). Over the whole range, the calibration coefficients are within $\pm 10 \%$. In Figure 11, the frequency distribution of the calibration coefficients for the radiation qualities CCRI, ISO $4037 \mathrm{H}$ is significantly above the mean of all calibration coefficients. This can be explained by the fact that 8 out of the 13 calibration coefficients in this group of radiation qualities belong to the CCRI $25 \mathrm{kV}$ radiation quality, which has the lowest 1st HVL $(\sim 0.25 \mathrm{mmAl})$ of all the radiation qualities used in this investigation. Because of the low response of the PTW Diados at this low HVL, the calibration coefficient is significantly higher than at higher HVLs (see Figure 7).

\section{Unfors 508}

Among the four instruments investigated in this project, the Unfors 508 shows the largest energy dependence of the calibration coefficients (see Figure 8). At the HVL of $x=0.3 \mathrm{mmAl}$, the calibration coefficient has a gradient of about:

$$
\frac{\left(d N_{k} / N_{k}\right)}{d x} \approx \frac{-1.5 \%}{0.01 \mathrm{mmAl}}
$$

In a mammographic set with Mo-anode and $30 \mu \mathrm{m}$ Mo-filter, for instance, the 1st HVL changes from about 0.28 to about $0.37 \mathrm{mmAl}$, if the tube voltage is changed from 25 to $35 \mathrm{kV}$. However, the calibration coefficient of the dosemeter changes in this range by about $-13 \%$. This means that the user of this instrument has to have a fairly good knowledge of the HVL in order to apply the correct calibration coefficient.

\section{CONCLUSION}

Four different instruments used in the dosimetry of mammography were calibrated by 13 metrological institutes within the framework of the EUROMET project no. 526. A large variety of radiation qualities was used to investigate the suitability of these qualities for the calibration of the instruments and to compare the calibration results among the laboratories. The results indicate that calibration coefficients for different radiation qualities do not differ significantly for instruments with small energy dependence. In such a case, the HVL of the radiation quality used for the calibration is not crucial. However, for instruments with a large energy dependence, the calibration result depends not only on the HVL, but also to some extent on the spectrum of the radiation quality used. In addition, differences in the procedure of the determination of the HVL at the individual laboratories could also contribute to the larger spread of the calibration coefficients for instruments with a pronounced energy dependence of response.

No significant difference in the response to $\mathrm{X}$ ray qualities produced with pulsed and constant potential $\mathrm{X}$ ray tubes with Mo-anode was noticed for any of the dosemeters investigated in this project.

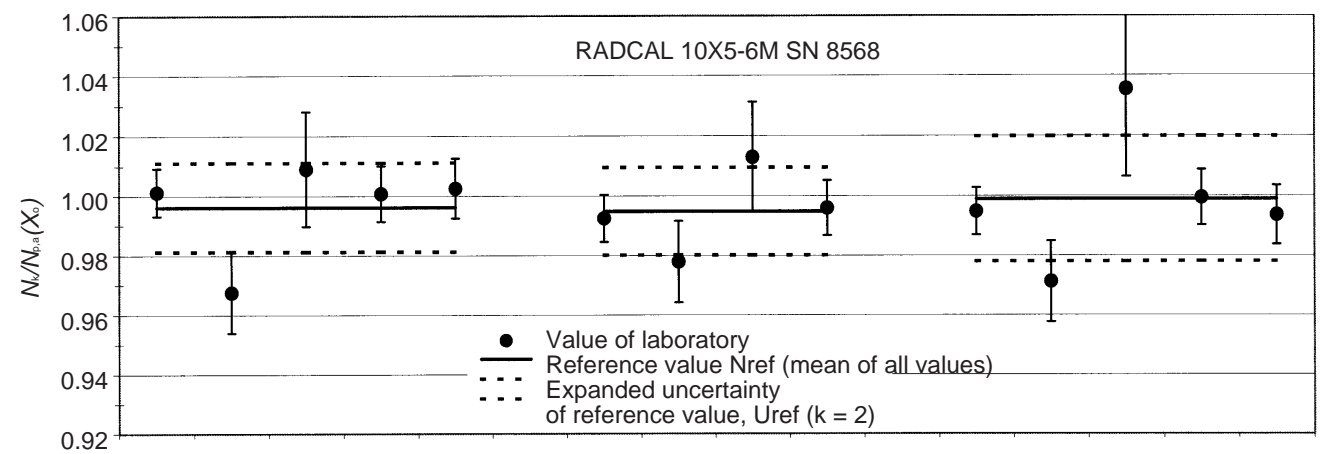

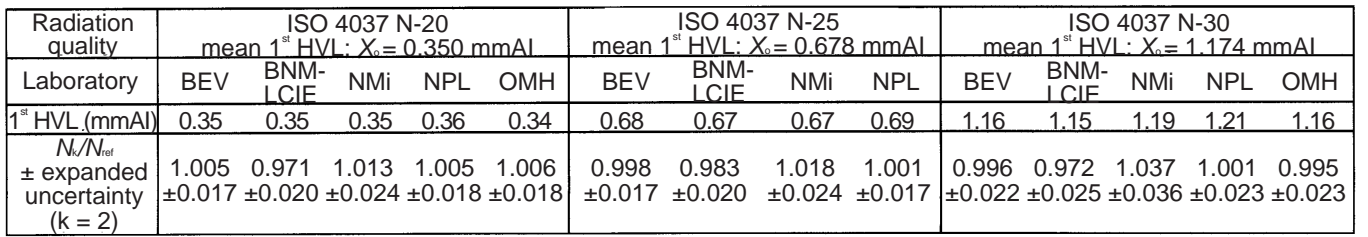

Figure 16. Ratio of air kerma calibration coefficients $N_{\mathrm{k}}$ and the value of the polynomial regression $N_{\mathrm{p}, \mathrm{a}}\left(x_{\mathrm{o}}\right)$ of all air kerma calibration coefficients at the mean 1st HVL $x_{\mathrm{o}}$ of radiation qualities defined by the international standard ISO 4037-1:1996 (narrow spectrum series) at a constant tube voltage for Radcal chamber. Note: The mean 1st HVL was calculated from the 1st HVL of radiation qualities from primary standard laboratories. 


\section{CALIBRATION OF DOSEMETERS USED IN MAMMOGRAPHY}

In many cases, the accuracy of a dose measurement in mammography does not only depend on the uncertainty of the calibration coefficient for the radiation quality chosen for the calibration of the dosemeter, but also on the shape of the response function of the dosemeter with respect to the radiation energy. The participants of this EUROMET project therefore draw the following conclusions:

(1) In general, the smallest uncertainty for the clinical measurement can be achieved with an instrument which shows a flat energy dependence of the response. Ionization chambers designed for mammography measurements which come close to this requirement are available. In this case, one can fully take advantage of the fact that (almost) any radiation quality with an HVL in the mammographic range can be used for calibration without compromising the quality of the clinical measurement. Such a dosemeter will always indicate the correct dose, irrespective of the HVL of the clinical beam. Furthermore, with such an instrument, the HVL can be determined with the smallest uncertainty.

(2) However, if a dosemeter with a marked energy dependence has to be calibrated, the following points should be taken into account:

(a) The best choice for calibration is a radiation quality with a spectrum as close as possible to the clinical beam that is intended to be measured. This will generally be a radiation quality based on a Mo- or Rh-target and a Moor Rh-filter.

(b) If an X ray tube with a Mo- or Rh-target is not available, a good compromise for calibration might be a radiation quality based on a $\mathrm{W}$-target and a Mo- or Rh-filter (as used in this work) followed by the radiation quality $\mathrm{H}-30$ from the ISO 4037 High Air Kerma Rate Series and the radiation quality CCRI $25 \mathrm{kV}$. These radiation qualities can be delivered with a fairly high dose rate-desirable when calibrating mammographic dosemeters. However, in this case, the radiation qualities used in calibration and in the clinical measurement are different and the possible influence of the energy dependence of the dosemeter on the measurements in the clinic should be carefully checked.

(c) The radiation qualities from the ISO 4037 Narrow Spectrum Series (i.e. N-20, N-25, $\mathrm{N}-30$ ) have the following shortcomings when used for the calibration of mammographic dosemeters: the dose rate of these qualities is considerably lower than that of the other radiation qualities discussed above, and for some detectors, the dose rate might not be sufficient in order to perform a proper calibration.

\section{ACKNOWLEDGEMENTS}

The authors would like to express their particular thanks to all the laboratory staff who contributed to this project. Commercially available instruments were identified and used in this investigation. Such identification implies neither recommendation or endorsement, nor that the equipment identified is necessarily the best available for the purpose.

\section{REFERENCES}

1. European Union. Council Directive 97/43/Euratom of 30 June 1997 on health protection of individuals against the dangers of ionizing radiation in relation to medical exposure, and repealing Directive 84/466/Euratom. Official journal No. L 180, 09/07/1997, 0022-0027.

2. Dosimetry in Diagnostic Radiology. In: Proceedings of a Seminar, Luxembourg, 19-21 March 1991. Radiat. Prot. Dosim. 43(1-4) (1992).

3. van Dijk, E. and de Vries, W. Results of the comparison of primary air kerma standards for $x$-ray qualities used in diagnostic radiology. (NMi Van Swinden Laboratorium) EUROMET 364. Report nr. S-TS-2000-10.

4. DeWerd, L. A., Micka, J. A., Laird, R. W., Pearson, D. W., O'Brien, M. O. and Lamperti, P. The effect of spectra on calibration and measurement with mammographic ionization chambers. Med. Phys. 29(11), November 2002.

5. International Electrotechnical Commission. Acceptance tests: imaging performance of mammographic $X$-ray equipment. IEC 1223-3-2, first edition, 1996-10.

6. International Electrotechnical Commission. Medical diagnostic X-ray equipment: radiation conditions for use in the determination of characteristics. IEC 1267, first edition, 1994-09.

7. Bureau International des Poids et Mesures. Qualités de rayonnement. BIPM - CCEMRI(I) R15 (1972).

8. International Organization for Standardization. $X$ and gamma reference radiation for calibrating dosemeters and doserate meters and for determining their response as a function of photon energy. Part 1: Radiation characteristics and production methods. ISO 4037-1 (1996).

9. International Electrotechnical Commission. Medical electrical equipment: dosimeters with ionization chambers andlor semiconductor detectors as used in X-ray diagnosis imaging. IEC 61674 (1997). 